\title{
CUKUL ESTATE: Perkembangan dan Dampaknya Bagi Buruh Petik Tahun 1972-2007
}

Oleh:

Temi Setiabudi ${ }^{1}$

\begin{abstract}
ABSTRAK
Perkebunan PT. Tatar Anyar Indonesia (Cukul Estate) merupakan satu dari sekian banyak perkebunan teh yang ada di Jawa Barat. Dalam perkembangannya perkebunan teh memiliki sejarah panjang dalam persebaran perkebunan teh di Indonesia, mulai dari Belanda dan nantinya diikuti oleh pengusaha lain dari berbagai negara sesuai dengan pembabakan sejarah yang ada. Khusus untuk perkebunan Cukul, terjadi beberapa kali perpindahan kepemilikan. Mulai dari 1948-1965 dikelola oleh perusahaan Inggris dengan nama P \& T Land (Pemanukan dan Tjiasem Land), 1965-1972 melalui proses nasionalisasi perusahaan perkebunan milik Inggris ini diserahkan pengelolaannya kepada Perusahaan Perkebunan Subang, 1972-2007 melalui Peraturan Pemerintah No.3/1971 perkebunan Cukul dikelola oleh PT. Tatar Anyar Indonesia melaui join venture antara perusahaan Asing (Inggris) dengan pihak swasta nasional. Keberadaan perkebunan Cukul memberikan dampak bagi perekonomian masyarakat sekitar melalui penyerapan tenaga kerja. Dalam hal ini, buruh petik menjadi bagian penting dalam melakukan proses produksi teh. Kebijakan perkebunan untuk buruh petik ini ditujukan pada kesejahteraan buruh petik melalui pemberian fasilitas-fasilitas antara lain bidang kesehatan, pendidikan dan jaminan sosial lainnya (tunjangan hari libur) dengan tujuan agar kehidupan buruh lebih sejahtera. Namun realita di lapangan sangat memprihatinkan, banyak di antara buruh yang kurang sejahtera, dimana perhatian terhadap anak buruh masih kurang, tidak semua anggota keluarga mendapatkan pelayanan kesehatan.
\end{abstract}

Kata Kunci: Perkebunan PT. Tatar Anyar Indonesia, buruh petik teh.

\begin{abstract}
The plantation of PT. Tatar Anyar Indonesia (Cukul Estate) is one of the many tea plantations in West Java. In the next developtment tea plantations has a long history in the distribution of tea plantations in Indonesia, from the Netherlands and will be followed by other businessmen from various countries in accordance with the existing historical period. Especially for plantation Cukul, occur several times of ownership. Starting from 1948-1965 managed by the British company under the name $P$ \& $T$ Land (Pemanukan and Tjiasem Land), in 1965-1972 through the process of nationalization of the British-owned plantation company has handed over its management to Subang Plantation Company, from 1972 to 2007 through a
\end{abstract}

${ }^{1}$ Temi Setiabudi adalah mahasiswa Pendidikan Sejarah FPIPS UPI. Penulis dapat dihubungi melalui No. Hp. 082218127475 atau email ke: temisetiabudi@rocketmail.com. 
Government Regulation No.3 / 1971 Cukul plantations managed by PT. Tatar Anyar Indonesia through the joint venture between the foreign company (UK) with the national private. The existence of Cukul plantations give effect to the economy of surrounding communities through employment. In this case, tea pickers become an important part in the process of tea production. For the farmer, policies aimed at to increase the welfare through the provision of facilities such as health, education and other social security (holiday allowance) for the workers' prosperous life. But the reality is very alarming, many of the workers less prosperous, still lacking attention to child labor, not all family members get health care.

Keywords: Plantation PT. Tatar Anyar Indonesia, tea pickers.

\section{PENDAHULUAN}

Perkembangan perkebunan di Indonesia tidak dapat dilepaskan dari peran kaum penjajah, terutama Belanda. Masuknya Belanda ke Indonesia, menjadikan masyarakat mengenal sistem perkebunan yang semula hanya mengenal sistem kebun dan tegal dalam mengusahakan tanahnya, mulai diperkenalkan dengan sistem perkebunan (Mubyarto: 1992, hlm 27). Sistem kebun yang berkembang merupakan bagian dari sistem pertanian tradisional, seringkali hanya sebatas pelengkap dari kegiatan pertanian. Sistem kebun biasanya diwujudkan dalam bentuk usaha kecil, tidak padat modal, penggunaan lahan terbatas, dan sumber tenaga kerja berpusat pada anggota keluarga. Berbeda dengan sistem perkebunan, dimana perkebunan merupakan bagian dari sistem perekonomian pertanian komersial dan kapitalistik yang mewujudkan usaha pertanian skala besar dan kompleks, bersifat padat modal (capital intensive), penggunaan areal pertanahan luas, dan organisasi tenaga kerja besar (Kartodirdjo dan Suryo: 1991, hlm. 4).

Di Indonesia, perkebunan berkembang dengan cepat dan luas, karena perkebunan memiliki peran dan kedudukan yang penting dalam menghasilkan devisa negara. Salah satu jenis perkebunan tersebut adalah perkebunan teh. Peranannya cukup besar dalam menunjang perekonomian nasional. Abu Mufakir (2011: hlm. 10), mengatakan bahwa teh sebagai sektor industri padat karya, industri teh di Indonesia pada tahun 1999 saja telah menyerap 300.000 pekerja dan menghidupi 1,2 juta jiwa. Di samping itu, teh berperan sebagai komoditi ekspor Indonesia sebagai penghasil devisa negara selain minyak dan gas (Yusroni, 2012, Th). Untuk 
persebarannya, perkebunan teh berada di berbagai daerah yang memiliki topografi pegunungan-pegunungan dengan udara yang sejuk. Jawa Barat memiliki luas terbesar dalam penanaman perkebunan khususnya komoditi teh. Salah satu perkebunan teh yang ada adalah perkebunan teh Cukul yang terletak di Desa Sukaluyu Kecamatan Pangalengan Kabupaten Bandung, Jawa Barat. Salah satu perkebunan tersebut adalah perkebunan yang dikelola oleh PT. Tatar Anyar Indonesia (sekarang dikelola oleh PT. Agropangan Putra Mandiri yang berpusat di Sentul, Bogor).

Keberadaan perkebunan teh Cukul memberikan gambaran bahwa terdapat hubungan yang sangat kuat antara pemilik perkebunan dalam hal ini manajer dengan buruh petik secara khusus. Aspek buruh bersama-sama dengan faktor modal berpengaruh terhadap produksi perkebunan. Perkebunan tidak bisa menghasilkan produksi apabila tidak ada buruh. Posisi patron selalu lebih menguntungkan karena memiliki segalanya, pengaruh dan sumber daya yang dapat dipergunakan untuk mengayomi, melindungi, serta memberikan bantuan terhadap posisi di bawahnya yaitu klien. Posisi klien yang selalu di bawah, hanya mampu membalas kebaikan seorang patron melalui usahanya menyediakan barang dan jasa yang diperlukan patron. Sehingga terjalin sebuah hubungan yang tidak terpisahkan untuk saling mnguntungkan satu sama lainnya. Terjadi ikatan yang saling bergantung antara pemilik perkebunan dengan para buruh. Sehingga dalam penyerapan tenaga kerja perkebunannya, PT. Tatar Anyar Indonesia menarik tenaga kerja yang berasal dari lingkungan sekitar perkebunan.

Dalam melakukan sistem perekrutan buruh di Perkebunan PT. Tatar Anyar Indonesia sangat mudah, tidak ada persyaratan khusus bagi calon buruh yang mau bekerja seperti pendidikan, usia maupun tinggi badan. Dengan tidak adanya syarat khusus bagi buruh, siapapun bisa bekerja di perkebunan. Bagi mereka bekerja di perkebunan merupakan suatu tonggak kehidupan. Sebab perkebunan memberikan lapangan pekerjaan yang diharapkan dapat memberikan suatu perubahan secara sosial-ekonomi ke arah yang lebih baik. Ironisnya buruh 
petik yang bekerja dengan segenap tenaganya tetap saja tidak mengalami perubahan taraf hidup yang signifikan.

Berbagai upaya dilakukan PT. Perkebunan Cukul untuk membantu kehidupan buruh, namun upaya perkebunan ini tidak membuat kehidupannya lebih baik bahkan jauh dari kata sejahtera.

Buruh petik teh merupakan pelaku produksi yang berada di bagian paling bawah dan terlemah dalam mata rantai produksi teh yang cukup panjang, hidup dalam kemiskinan yang turun temurun dan kondisi kerja yang buruk (Mufakhir, 2011 hlm. 12). Kehidupan buruh petik dengan penghasilan kecil serta kehidupan dari tahun ke tahun yang tidak mengalami perubahan. Disatu sisi muncul permasalahan dimana perkebunan dengan segala upayanya memberikan kesejahteraan terhadap buruhnya, dan disisi lain buruh masih belum sejahtera, apa yang menjadi faktor penyebabnya? perlu kajian lebih mendalam akan hal tersebut. Oleh karena itu artikel ini mengangkat masalah tersebut dengan topik "Perkembangan PT. Perkebunan Teh Tatar Anyar Indonesia (Cukul Estate) dan Dampaknya Terhadap Kehidupan Buruh Petik Tahun 1972-2007”.

\section{METODE PENELITIAN}

Metode yang digunakan dalam penelitian ialah menggunakan metode historis. Menurut Ismaun (2005, hlm. 34), metode historis merupakan rekontruksi imajinatif mengenai gambaran masa lampau peristiwaperistiwa sejarah secara kritis dan analitis berdasarkan bukti-bukti dan data peninggalan masa lampau yang disebut sumber sejarah. Dalam merekontruksi gambaran masa lampau tersebut. Peneliti menggunakan cara dan langkah yang diambil dari pendapat Helius Sjamsuddin (2012) ada enam tahap yang harus ditempuh dalam penelitian sejarah. Langkahlangkah tersebut adalah sebagai berikut:

1. Memilih satu topik yang sesuai;

Dalam memilih topik perlu kiranya memperhatikan nilai, keaslian, kepraktisan serta kesatuan dari topik tersebut.

2. Mengusut semua evidensi (bukti) yang relevan dengan topik;

3. Membuat catatan yang dianggap penting;

4. Mengevaluasi secara kritis semua evidensi yang telah dikumpulkan (kritik sumber); 
5. Menyusun hasil-hasil penelitian kedalam suatu pola yang benar sesuai sistematika;

6. Menyajikannya dalam suatu cara yang dapat menarik perhatian dan mengkomunikasikan kepada para pembaca sehingga dapat dimengerti sejelas mungkin (hlm. 70).

Lebih lanjut Helius Sjamsuddin (2012, hlm. 71) menyederhanakan keenam langkah di atas menjadi tiga langkah besar yang sering kita temui, langkah tersebut merupakan penjabaran dari Heuristik, Kritik dan Historiografi. Untuk langkah memilih topik, mengusut semua evidensi dan membuat catatan penting jika dianalisis ini masuknya kedalam langkah heuristik. Mengevaluasi secara kritis semua evidensi merupakan kritik terhadap sumber. Sedangkan menyusun hasil-hasil penelitian dan menyajikannya masuk

\section{HASIL PENELITIAN DAN PEMBAHASAN}

Perkebunan PT. Tatar Anyar Indonesia merupakan salah satu perkebunan yang membudidayakan tanaman teh berada dalam wilayah Kabupaten Bandung. Secara geografis wilayah kabupaten Bandung terletak kedalam historiografi. Namun dalam historiografi ini ada langkah interpretasi terlebih dahulu.

Adapun teknik yang digunakan dalam penelitian ini berupa studi literatur dan wawancara. Studi literatur berdasarkan sumber-sumber buku yang didapatkan serta dokumendokumen dan arsip yang berkaitan dengan topik yang diambil. Sedangkan pendekatan multidisipliner digunakan untuk menghubungkan atau memadukannya dengan ilmu-ilmu lainnya yang serumpun yaitu ilmuilmu sosial. Beberapa konsep ilmu sosial yang peneliti gunakan adalah pendekatan sosiologis atau ilmu sosial, ekonomi maupun politik yang berkaitan dengan kebijakan pemerintah terhadap perkebunan, buruh/tenaga kerja serta sistem upah yang berlaku.

di antara $6^{0} 41^{\prime}-7^{0} 19^{\prime}$ Lintang Selatan dan $107^{0} 22^{\prime}-108^{0} 5^{\prime}$, Bujur Timur dengan luasnya $176.239 \mathrm{Ha}$ atau $1762,39 \mathrm{KM}^{2}$. 


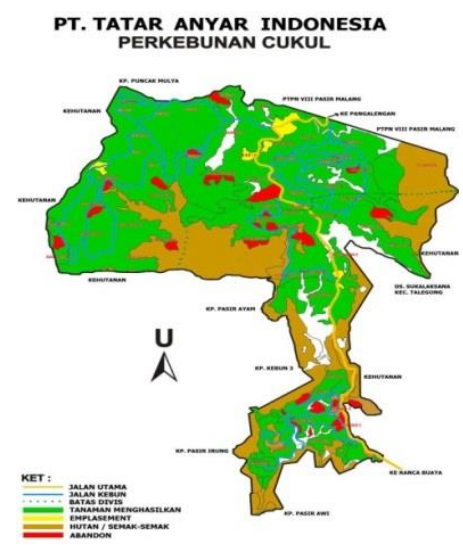

\section{PetaWilayah Perkebunan Teh}

Cukul yang Dikelola PT. Tatar

Anyar Indonesia

Sumber: Diolah oleh PT. Perkebunan

Teh Cukul Tahun 2009.

Perkebunan Cukul sendiri tersebar di dua kabupaten. Bisa dilihat pada peta di samping, ada Desa
Sukalaksana Kecamatan Talegong untuk bagian yang ada di kabupaten Garut dan Kecamatan Pangalengan itu sendiri. Selain itu, dikelilingi oleh kawasan hutan lindung yang sangat luas. Perkebunan ini untuk memudahkan pengelolaannya, dibagi ke dalam 4 afdeling. Keempat afdeling tersebut di antaranya Afdeling Cukul, Afdeling Bunikasih, Afdeling Kidang dan Afdeling TBM (Tanaman Belum Menghasilkan). Setiap Adeling memiliki luas yang berbeda di antara satu sama lain. Untuk luasnya bisa dilihat dari tabel di bawah ini:

Tabel. 1

Luas Perkebunan PT. Tatar Anyar Indonesia 1972-2007

\begin{tabular}{|c|c|c|c|c|}
\hline \multirow[b]{2}{*}{ Tahun } & \multicolumn{2}{|c|}{ Tanaman Teh } & \multirow[b]{2}{*}{$\begin{array}{c}\text { Lahan Cadangan } \\
\text { (Ha) }\end{array}$} & \multirow[b]{2}{*}{$\begin{array}{c}\text { Total HGU } \\
\text { ( Ha) }\end{array}$} \\
\hline & $\begin{array}{r}\text { TM } \\
\text { (Ha) }\end{array}$ & $\begin{array}{c}\text { TBM } \\
\text { (Ha) }\end{array}$ & & \\
\hline 1972 & 622,50 & - & 623,44 & $1.245,94$ \\
\hline 1977 & 569,89 & - & 676,05 & $1.245,94$ \\
\hline 1982 & 558,04 & - & 687,90 & $1.245,94$ \\
\hline 1987 & 501,56 & - & 744,38 & $1.245,94$ \\
\hline 1992 & 535,58 & - & 710,36 & $1.245,94$ \\
\hline 1997 & 799,76 & 24,78 & 421,40 & $1.245,94$ \\
\hline 2002 & 726,48 & 48,50 & 470,96 & $1.245,94$ \\
\hline 2007 & 712,39 & - & 533,55 & $1.245,94$ \\
\hline
\end{tabular}

Sumber: Arsip Perkebunan PT. Tatar Anyar Indonesia, Areal Statement Kadastral Tahun 2015 
Berdasarkan tabel di atas, diperoleh informasi bahwa luas areal perkebunan teh PT. Tatar Anyar Indonesia memiliki luas Hak Guna Usaha (HGU) 1.245, 94 Ha. Yang dimaksud dengan HGU merupakan suatu lahan yang digunakan suatu perusahaan perkebunan PT. Tatar Anyar Indonesia untuk perkebunan Cukul yang telah memiliki izin sewa dari negara melalui pemerintah daerah dimana tanah itu berada. Pada tabel 4.1, terlihat bahwa areal yang digunakan untuk tanaman teh dari jumlah keseluruhan HGU hanya kisaran $50 \%$ saja, terlihat pada luas perkebunan tahun 1972 untuk tanaman menghasilkannya (TM) sekitar 622,50 Ha yaitu setengahnya dari total HGU dimana sisanya sebagai lahan cadangan. Lahan cadangan yang dimaksud merupakan lahan yang digunakan untuk keperluan lain seperti perumahan buruh, jalan, semaksemak, situ, perkebunan non teh (tanaman kopi) dan lain-lain.

$$
\text { Dalam perkembangannya, }
$$
perkebunan teh Cukul dikembangkan oleh orang Inggris. Berbicara mengenai sejarah perkebunan teh PT. Tatar Anyar Indoneisa tidak banyak informasi yang di dapatkan. Hal ini dikarenakan banyaknya arsip yang hilang serta kurangnya perhatian pengelola mengenai perkembangan perkebunan dari masa ke masa. Peneliti menemukan data yang tercatat dalam arsip perkebunan bahwa sejak periode tahun 1948-2007 sudah 3 kali pindah tangan kepemilikan. Peralihan kepemilikan ini sebagai berikut.

1. Periode tahun 1948-1965 dikelola oleh perusahaan P \& $\mathrm{T}$ Land (Pemanukan dan Tjiasem Land).

2. Periode tahun 1966-1972 dikelola oleh Perusahaan Perkebunan Subang (PP Subang).

3. Periode tahun 1972-2007 dikelola oleh PT. Tatar Anyar Indonesia yang didalamnya terdiri dari beberapa pemegang saham.

Pasca kemerdekaan Indonesia, terjadi proses nasionalisasi beberapa perkebunan. Proses nasionalisasi ini berdasarkan kepada Keputusan Presiden Republik Indonesia nomor: 6/1964 tertanggal 26 November 1964 , maka semua perusahaan-perusahaan milik Inggris yang ada dalam wilayah negara Republik Indonesia, diakui sepenuhnya secara langsung serta 
diurus oleh pemerintah pusat. Dengan adanya keputusan ini, dirasakan pula oleh perkebunan Cukul yang pada periode tahun 1948-1965 dikelola oleh perusahaan Inggris yang bernama P \& $\mathrm{T}$ Land (Pemanukan dan Tjiasem Land). Pengelolaan perkebunan yang dinasionalisasi dari perusahaanperusahaan Inggris ini diserahkan kepada Departemen Perkebunan. Dengan demikian sebagai pelaksana tersebut dalam bulan Desember 1964, Mentri Koordinator Kompartemen Pertanian dan Agraria telah menyerahkan perusahaan-perusahaan Perkebunan Dwikora kepada Mentri Perkebunan. Perusahaan Dwikora merupakan perusahaan perkebunan bekas milik Inggris yang dijadikan tujuh kelompok kesatuan yang menginduk kepada BPU (Badan Pimpinan Pusat) yang berkedudukan di Jakarta (Sonjaya, 2011: hlm. 80). Kemudian perusahaan Dwikora ini dikelola oleh PP Subang (Perusahaan Perkebunan Subang) termasuk perkebunan Cukul.

Pada tahun 1972 pengelolaan kembali kepada swasta dengan modal yang cukup besar yaitu PT. Tatar Anyar Indonesia. Asep Rahmat (40 tahun) mengungkapkan:

\begin{abstract}
Pada perkembangannya perkebunan Cukul ini mengalami beberapa pindah tangan yang salah satunya pada tahun 1972, melalui peraturan pemerintah No. 3 tahun 1972 perkebunan Cukul dikelola oleh perusahaan PT. Tatar Anyar Indonesia yang di dalamnya merupakan kerja sama (joint venture) antara swasta nasional dan asing. Yaitu antara pengusaha Indonesia dengan perusahaan Inggris.
\end{abstract}

Pengelolaan yang dilakukan oleh PT. Tatar Anyar Indonesia terus berlanjut hingga tahun 2007, dalam masa kurun waktu tersebut produksi secara terus menerus dilakukan. Jenis teh yang diproduksi adalah teh hitam CTC (Crushing Tearing Curling). Teh hitam adalah teh kering hasil pengolahan pucuk dari daun muda yang terdiri pucuk p+3 sampai dengan p+5 daun muda dari tanaman Camellia Sinensis. Adapun jenis-jenis hasil produksi teh kering di perkebunan PT. Tatar Anyar Indonesia adalah : BP 1 (Broken Peko 1), PF 1 (Peko Panning 1), PD (Peko Dust), D 1 (Dust 1), FANN (Fanning), D 2 (Dust 2), D 3 (Dust 3), dan BMF (Broken Mixed Fanning). Sedangkan untuk pemasaran produk teh perkebunan Cukul atau PT. Tatar Anyar Indoensia lebih banyak untuk keperluan ekspor, 
sisanya untuk keperluan dalam negeri. Perbandingan jumlah keperluan dalam dan luar negeri 6:4 atau sekitar 60\%$70 \%$ untuk ekspor dan sisanya dipasarkan di dalam negeri.

Proses pemasaran hasil teh dari perkebunan ini terlihat menarik apabila dibandingkan dengan pemasaran teh yang dilakukan oleh beberapa perkebunan yang ada di Indonesia terutama perkebunan milik negara, pemasaran hasil produksi teh di perkebunan Cukul tidak langsung ke tangan konsumen, melainkan melalui pusat terlebih dahulu. Setelah tersimpan di gudang, sebelum adanya surat perintah pengangkutan dari pusat teh tidak akan dikeluarkan (dijual). Setelah adanya surat dari pusat baru teh kering akan dikeluarkan dan diangkut ke pusat. Setelah berada di gudang pusat, teh akan dipasarkan ke berbagai negara dan pasar dalam negeri dengan perbandingan yang telah dijelaskan sebelumnya (wawancara dengan bapak Asep Rahmat selaku Kepala Tanaman, 23 Desember 2015).

Hasil produksi pada perkebunan tersebut tidak terlepas dari peran tenaga kerja/buruh. Perkebunan PT. Tatar Anyar Indonesia dalam menyerap tenaga kerja tidak merekrut dari luar lingkungan perkebunan, tujuannya agar jangkauannya lebih dekat. Selain itu, faktor turun temurun menjadi bagian penting dalam sistem perekrutan tenaga kerja terutama untuk buruh petik. Berbeda dengan perekrutan untuk pegawai di kantor, bisa berasal dari luar daerah apalagi untuk posisi jabatan administratur (manajer). Penunjukan manajer biasanya dilakukan oleh direktur utama atau pimpinan pusat dengan sistem rolling dari perkebunan satu ke perkebunan lain. Dalam klasifikasinya, buruh petik dan staf dibedakan kedalam 3 (tiga) jenis, yaitu dapat dilihat pada tabel berikut ini: 
Tabel 2

Rata-Rata Jumlah Buruh di Perkebunan Cukul Tahun 1972-2007

\begin{tabular}{|c|l|c|c|c|c|}
\hline \multirow{2}{*}{ No. } & \multirow{2}{*}{ Status Buruh } & \multicolumn{4}{c|}{ Tahun } \\
\cline { 3 - 6 } & & 1970an & 1980an & 1990an & 2000an \\
\hline 1 & Harian Tetap (SKU) & 704 & 670 & 665 & 493 \\
\hline 2 & Harian Lepas (Musiman) & 480 & 456 & 495 & 590 \\
\hline 3 & Pegawai Kantor (Bulanan) & 16 & 14 & 15 & 17 \\
\hline \multicolumn{2}{r}{ Total } & 1200 & 1140 & 1175 & 1100 \\
\hline
\end{tabular}

Sumber: Wawancara dengan Bapak Ade Atip pensiunan Juru Tulis PT. Tatar Anyar Indonesia (Cukul Estate), 08 Januari 2015.

Menariknya bahwa mayoritas pekerja dalam perkebunan teh adalah buruh petik dengan jenis kelamin perempuan dengan status harian lepas maupun harian tetap. Untuk perkebunan PT. Tatar Anyar Indonesia dalam bentuk tanggung jawabnya terhadap lingkungan dan masyarakat, dapat dilihat dengan adanya beberapa fasilitas yang dibangun agar dirasakan langsung oleh pekerja kebun. Fasilitas-fasilitas yang diberikan perusahaan ini di antaranya:

1) Lembaga Pendidikan. Bentuk tanggung jawab perkebunan dalam mencerdaskan kehidupan bangsa umumnya generasi muda dan khususnya anak-anak pekerja perkebunan. Dengan adanya lembaga pendidikan Taman Kanak-kanak (TK) yang ada di lingkungan perkebunan ini, tidak heran kalau TK tersebut dimanfaatkan sebaik- baiknya untuk kepentingan pendidikan anak dan cucu buruh perkebunan. Biaya sekolah TK tidak dipungut atau gratis, guru atau tenaga pendidiknya dibayar oleh pihak perkebunan.

2) Balai Pengobatan Karyawan. Fasilitas lain yang diberikan perkebunan terhadap buruh yaitu fasilitas kesehatan salah satunya ialah dibangunnya balai pengobatan/klinik untuk menunjang kesehatan pekerja perkebunan. Berbicara mengenai kebijakan perkebunan dalam hal kesehatan, PT. Tatar Anyar memiliki beberapa kebijakan yang diterapkan, Retno (Wawancara, 2 Januari 2016) menjabarkan kebijakan tersebut di antaranya:
1) Biaya
pengobatan ditanggung oleh perusahaan; 
2) Apabila sakit pada saat bekerja, perusahaan akan tetap memberikan upah;

3) Memberikan pinjaman mobil untuk transportasi apabila mengharuskan ke rumah sakit;

4) Apabila sakit, buruh diperbolehkan untuk istirahat di Rumah;

5) Proses akses ke balai pengobatan mudah dilakukan.

Kebijakan yang diterapkan di atas merupakan suatu peran nyata perkebunan untuk menjaga agar buruh selalu sehat dan kuat bekerja. Tentu apabila buruh petik semua sehat dan kuat, maka produksi pucuk setiap harinya akan stabil bahkan cenderung meningkat. Namun apabila buruh banyak yang tidak bekerja karena sakit, perusahaan akan mengalami penurunan produksi.

3) Fasilitas di bidang sosial. Di samping fasilitas pendidikan dan kesehatan, bentuk tanggung jawab perusahaan perkebunan PT. Tatar Anyar Indonesia memberikan fasilitas dalam bidang sosial. Dalam bidang ini sudah di atur dalam undangundang ketenaga kerjaan seperti JAMSOSTEK dan lain-lain.
Jaminan sosial yang diberikan terhadap pekerja khususnya buruh petik dapat menjadi daya tarik untuk menciptakan semangat kerja, kesungguhan dalam bekerja. Di antara fasilitas tersebut meliputi rumah Bedeng, upah hari minggu/libur, libur Hari Raya, bonus harian, THR, tunjangan hari tua dan beberapa fasilitas lainnya.

Namun upaya di atas tidak menjadikan sebuah solusi untuk permasalahan kesejahteraan buruh, dalam bidang pendidikan tidak ada tindak lanjut bagi anak buruh setelah lulus dari TK untuk mendapatkan beasiswa sekolah lanjutan. Dengan upah yang relatif kecil buruh harus membiayai sekolah anaknya untuk melanjutkan ke jenjang SD, SMP dan SMA. Kebijakan dalam bidang kesehatan pun tidak banyak membantu buruh petik untuk menunjang kesehatan keluarganya. Fasilitas kesehatan hanya diperuntukan bagi yang bersangkutan saja yaitu buruh petik itu sendiri. Di luar itu apabila anak atau keluarga ada yang sakit harus ditanggung sendiri tanpa adanya bantuan dari perkebunan. Sedangkan fasilitas dalam bidang sosial banyak 
diperuntukan bagi buruh petik yang status pekerjaannya tetap (SKU). Bagi buruh petik yang statusnya harian lepas tidak semua fasilitas dalam bidang sosial dapat dirasakan. Sebagai contoh, buruh harian lepas tidak mendapatkan fasilitas berupa tunjangan hari raya (THR), upah hari minggu, dan lain-lain.

\section{SIMPULAN}

Berdasarkan hasil analisis dan pembahasan mengenai perkembangan dan dampak perkebunan Cukul (Cukul Estate) terhadap buruh petik tahun 1972-2007, dapat ditarik kesimpulan sebagai berikut:

1. Pada perkembangannya perkebunan PT. Tatar Anyar Indonesia (Cukul Estate) terjadi beberapa kali perpindahan kepemilikan, tercatat sejak tahun 1948-2007 sudah terjadi 3 kali pindah kepemilikan dengan kebijakan-kebijakan yang berbeda satu sama lainnya.

2. Produksi perkebunan Cukul tidak terlepas dari peran buruh petik. Buruh yang bekerja dalam setiap tahunnya berada pada kisaran 1000 orang yang terdiri dari buruh harian lepas/musiman, buruh tetap/SKU dan buruh bulanan yang di dalamnya adalah pekerja yang berada di kantor/pabrik.

3. Keberadaan perkebunan memberikan dampak terhadap perekonomian masyarakat melalui penyerapan tenaga kerja. Di samping itu, perkebunan memberikan kebijakan-kebijakan yang dikeluarkan untuk kesejahteraan buruh petiknya. Namun dengan berbagai kebijakan tersebut kehidupan buruh masih jauh dari kata sejahtera.

\section{DAFTAR PUSTAKA}

Ismaun. (2005). Sejarah sebagai ilmu. Bandung: Historia Utama Press

Kartodirdjo, S. dan Suryo, Djoko. (1991). Sejarah perkebunan di Indonesia: kajian sosialekonomi.Yogyakarta: Aditya Media.

Mubyarto, dkk. (1992). Tanah dan tenaga kerja perkebunan. Yogyakarta:Aditya Media

Sjamsuddin, H. (2012). Metodologi sejarah. Yogyakarta: Ombak.

Mufakhir, A. (2011). Perkebunan teh dan reproduksi kemiskinan. Jurnal Kajian Perubahan SEDANE Vol. 11 No. 1, Hlm. 10-20. 
Sonjaya, Sonya. (2011).

Perkembangan PT. Perkebunan Ciater dan dampaknya terhadap kehidupan sosial-ekonomi masyarakat Ciater tahun 19711996. (Skripsi). Pendidikan Sejarah UPI. Bandung. tidak diterbitkan.

Yusroni, Nanang Dkk. (2012). Kajian ekonomi industri pada usaha produksi perkebunan teh rakyat di Indonesia. (Artikel). Fakultas Ekonomi Universitas Wahid Hasyim. Semarang: tidak diterbitkan.

\section{Arsip}

Lembaran Data Realisasi Produksi Tahun 1990-2013 PT. Tatar Anyar Indonesia (Cukul Estate).
Lembaran Data Areal Statement Kadastral PT. Tatar Anyar Indonesia Tahun 1972-2007.

Lembaran Peta PT. Perkebunan Teh Cukul (PT. Tatar Anyar Indonesia.

Lembaran Sejarah Perkebunan PT. Tatar Anyar Indonesia Tahun 1972-2007

\section{Wawancara}

Ade Atip, Pensiunan Juru Tulis (55 Tahun), 2 Agustus 2015, 8 Januari 2016

Asep Rahmat, Kepala Tanaman (40 Tahun), 23 Desember 2015

Retno, Bagian Poliklinik (35 Tahun), 2 Januari 2016 